\title{
Community Participation-Based Environmental and Health Management in Dhaka City Suburban Slum Areas
}

\author{
Tupo Yaesin ${ }^{1}$, Mhotin Jobin ${ }^{2}$, Hussain Mahedi ${ }^{2}$ \\ Email: yaessin.tupoyes89@gmail.com \\ ${ }^{1}$ Environmental Health and Safety, Bangladesh University of Health Sciences, Bangladesh \\ ${ }^{2}$ Department of Environmental Management, University Grants Commission of Bangladesh \\ Received: December 10, 2021 \\ Revised: January 12, 2022 \\ Accepted: January 25, 2022
}

\begin{abstract}
The purpose of this article is to identify the role of the community in dealing with the problem of slum housing in the city of Dhaka with several approaches, namely collaboration between organizations and the role of the community itself. Several programs that have been implemented to solve this problem are public housing, slum reconstruction program, and Approach to Basteess. The potential of the impoverished to improve their living conditions and hence their productivity and income is demonstrated by the housing projects implemented by non-governmental organizations. Living under these conditions can lead to a variety of negative consequences, including decreased health, increased pollution, the spread of illness, and even criminal conduct. It is considered a disease in the city to have slums. It is considered a disease in the city to have slums. Build a residential environment that is conducive to various aspects of human progress in order to quickly achieve poverty reduction via comprehensive human development.
\end{abstract}

Keywords: Community Participation, Suburban Slum Areas, Environment, Health

Introduction

By comparison, the number of people who live in the city has increased more quickly than the growth of the infrastructure. people are looking for their own personal path to happiness, including, but not limited to, building a home with all the amenities they need. Any attempt by slum settlement to reach the city limits will unavoidably cause alarm in the city's sane residents. This has the effect of reducing the risk of vulnerability and social conflict, increasing the level of health care for the population, and reducing the quality of service provided infrastructure. As a result of this, residential slums must be addressed immediately, and the most basic slum settlements must be able to be verified. In addition, the current state of slum lands must be transformed into lands fit for human habitation and settlements that are safe, peaceful, tranquil, and free of danger.

Handling the environment for slum settlements, one of the ways the government is trying to get rid of it, is by implementing the Handling of the Housing Environment and Area-Based Slums that was put in place by the Central Government through the Ministry of State for Public Housing. The primary goal of this project is to maximize human potential by improving the quality of the environment and increasing the amount of energy available for use. This project has both technical and non-technical components; the technical components include repairs to residential properties or improvements to the city's infrastructure as a whole. Non-technical activities can include raising the general level of human knowledge, such as community education programs to raise the level of understanding that is required by the people in the community. There are two reasons why this participation is so important. First of all, in the 
context of human participation as a subject, human will not become a man if she is only an object. Second of all, in the context of human participation as a long term, it is not possible for a person to be a man if she is just an object.

Development must be protected against both mental and societal structures. In order to meet their needs, the population must be given the time and resources to identify their wants and needs and work diligently to overcome any obstacles that stand in their way. Mass education cannot be achieved by indoctrination; instead, it must be achieved through participation in one's own activities. This must be made clear to the people, because they already know so much about what they need.

The public must be educated about the importance of promoting healthy living through various forms of social media or government programs that are more focused on raising awareness among the general public, so that more people will feel motivated to protect and improve their health, or even to commit acts of violence to do so.

Those who are exposed to a healthy environment, such as a forest or a lake, are generally healthy, while those who are exposed to an unhealthy environment, such as a city or a highway, are more likely to suffer from a variety of illnesses, which can lead to a large number of deaths in the young population. TB, pneumonia, bronchitis, typhoid, dysentery, influenza, measles, smallpox, malaria, and more are some of the illnesses that come about because of the poor quality of the settlement's environment. Apart from economic issues, there are a number of environmental issues that are intertwined with one another, such as issues with the use of land guns, the treatment of workers, the provision of clean air and clean water, the construction of new homes, the preservation of natural resources like forests, and a host of others.

To this day, Dhaka remains the world's most populous city. There is just one issue that has to be addressed, and that is slum settlements. At least 12.5 percent of Dhaka's residents are located inside an area known for its low population density, where 750 people live per square mile, or around 12 percent of the city's overall population. In this region, there is a small amount of/nothing at all of assistance for the needs of the face, such as sanitation and drainage. It was in 1985 that the Local Government Engineering Department which had been established in five cities, was established to deal with issues relating to social and environmental issues that affected slum areas.

Local governments have achieved significant strides in providing the urban poor with basic physical, social, and economic infrastructure thanks to SIP's participatory approach. The SIP's microcredit program was the most successful and the most appealing of all of its components. Many low-income families have benefited from this service. SIP has had a tremendous impact on slum dwellers' health and sanitation knowledge, which has resulted in a large decrease in the number of illnesses. It is through community participation and savings and credit programs that SIP empowers impoverished women to realize their full potential as family members and members of the community.

The public's interest in the home environment has grown in recent years. Various government and community organizations hold a variety of seminars, work meetings, and gatherings. There are several policies, methods, and plans needed to address this complex problem, and they must be applied consistently and continually in order to provide a comprehensive solution.

\section{Methods}

In this research, the author relied on questionnaires to gather information. In this case, the writer categorizes the research as a survey in which the data is collected via the use of observation. Survey research is the most often utilized kind of research across all fields. Survey 
research is the process of gathering information about one or more groups of individuals - such as their traits, views, attitudes, or prior experiences - by posing questions to them and tabulating their responses.

Following the classification of code-switching into categories, the author did a percentage analysis to determine the total number of instances of code-switching throughout the work. In this stage, it refers to the process of counting the number of instances of code switching and the kind of code switching, as well as the process of determining the frequency of code switching. After then, the result of the counting is converted into a percentage value.

\section{Results and Discussion}

\section{Urban Poverty and Population Growth in Dhaka}

\section{Population and Urbanization}

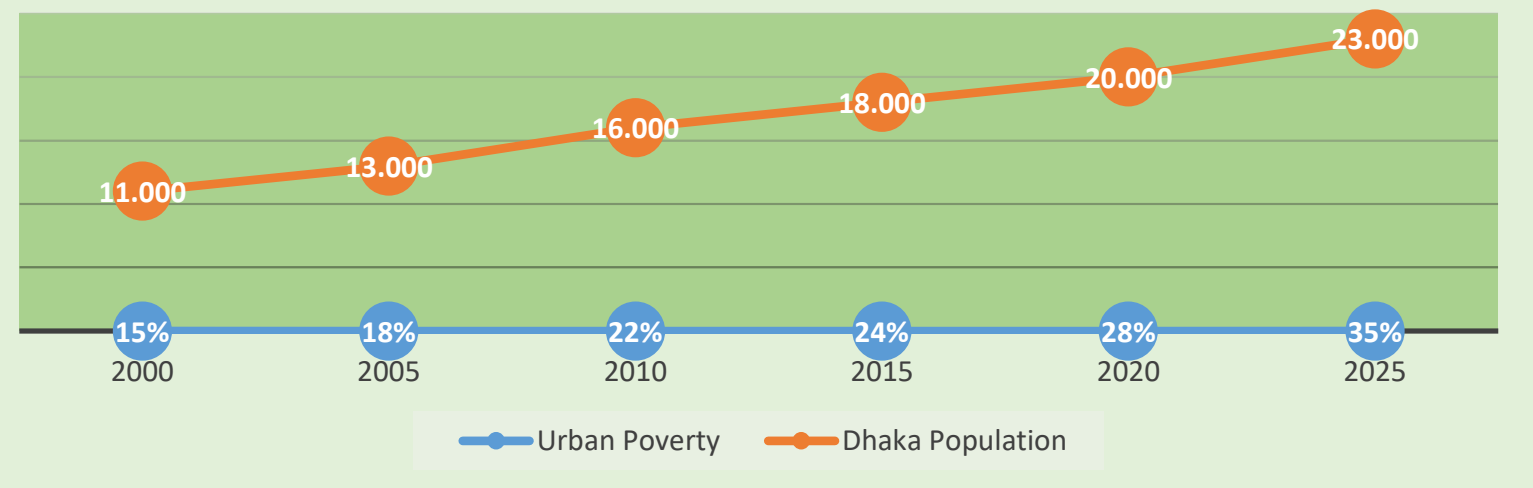

Figure 1. Population and Urban Growth

For the LIG, living in Bangladesh's cities is becoming increasingly challenging as a result of urbanization. This 16-million-person metropolis's population is up by 10 times in the previous three decades. The city receives an average of 350,000 impoverished migrants each year. Approximately 30 to 55 percent of Bangladesh's population resides in Bangladesh's major cities, with Dhaka's bastees (slum regions) housing 25 percent of the population in 1996 and 37.4 percent in 2003, respectively. 2156 bastees housed about 3 million people during the 1980s, rising to over 2800 in the next decade, and 3007 in the mid-'90s, according to the Bangladesh Bureau of Statistics.

Bastees are characterized by poverty, high density, a lack of infrastructure and amenities, illiteracy, criminality, environmental and psychological deterioration, and other problems. Rainwater covers 65 percent of this plant's habitat; it grows in landfills, open drains, embankments, lowlands, and along rail lines. Basteebashis in the informal sector endure poor earnings, long working hours, and the threat of losing their jobs due to lack of security. Among the impoverished in Dhaka, fewer than 5\% of the population is happy with 8 out of 11 services. In the absence of a settlement, utility companies are administering low-quality services from government, non-governmental organizations (NGOs), and private sources, frequently illegally. 


\section{Environmental Management}

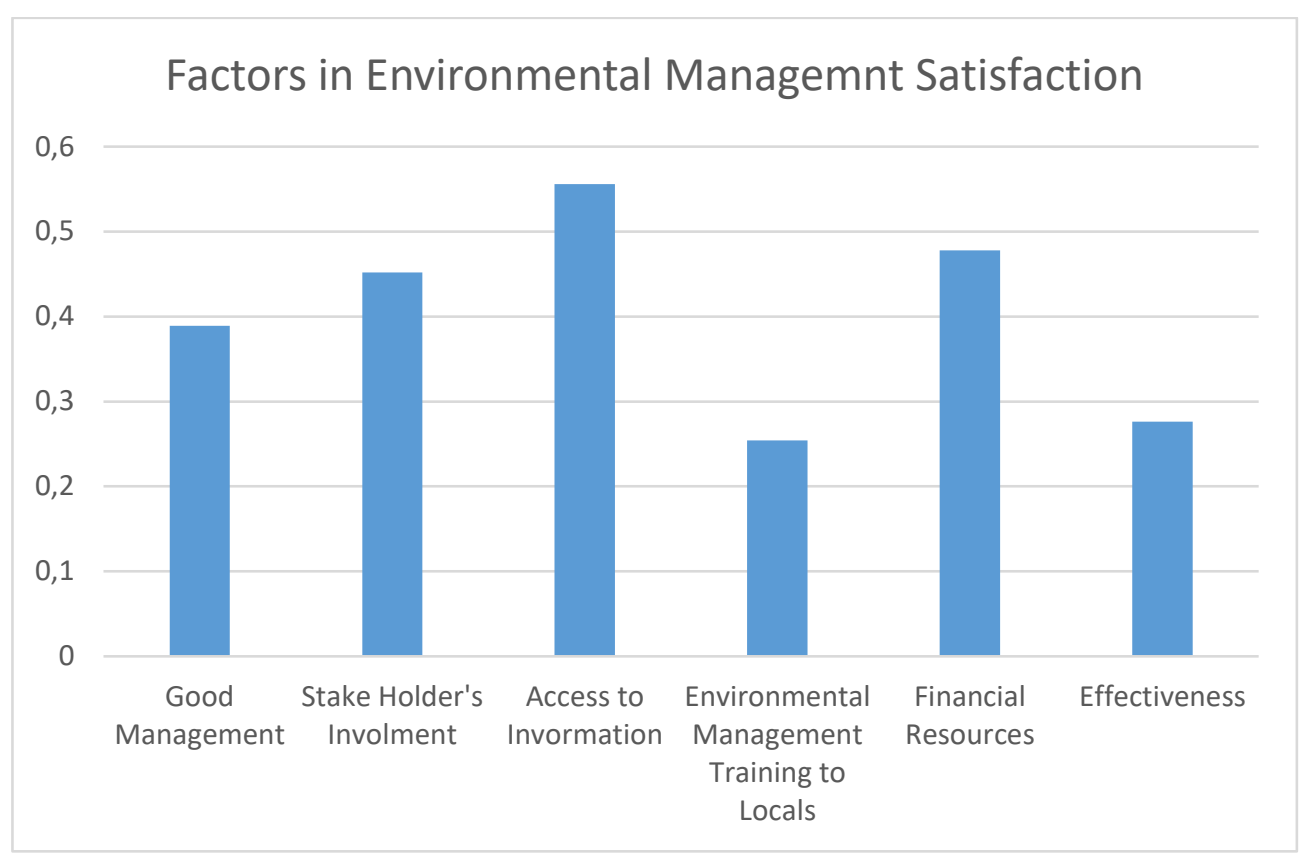

Figure 2. Locals Satisfaction Survey Results on Environmental Management

Large cities, including those in developing nations, are plagued with slums. The physical state of a slum community is one of three main considerations in a slum settlement research. It may be visible in a variety of ways: low-quality construction, unpaved and unpatterned roads, nonfunctioning sanitation and drainage and garbage that isn't adequately managed are just a few. Second, the social, economic, and cultural situations of the residents of these settlements. A culture of poverty pervades the lives of those who live in slums, as evidenced, amongst other things, by the people's indifferent attitudes and behaviors. Third, consider the results of these two circumstances. Poor health conditions, pollution, disease transmission and deviant behavior can all arise from living in these settings.

Slums are viewed as a sickness that must be fought against in the city. Settlement expansion is mostly driven by population increase. However, the quality of the settlements will be determined by the socio-economic conditions of the community and the abilities of the city management. As the population grows in poverty and the government is unable to manage expansion and provide basic urban amenities, slums are the result.

There are several issues to consider when it comes to planning for the growth of urban activities, including how to accept, regulate, and utilize migrants in the city's spatial planning system. Because of this, there are pockets of activity that do not sustain each other, and slum communities are developed.

Due to the above-mentioned population issues and the government's restricted budget for urban planning and administration, housing and settlement amenities have also been limited and expensive to finance. Low-income or "poverty" persons are the ones most likely to be unable to meet their housing and settlement demands in metropolitan environments. When a person's basic requirements such as food, clothing, and medical care are in jeopardy, the first thing they cut is the money they spend on their housing and living arrangements.

There is a dilemma for individuals who are poor and have low incomes: they can't ignore the pressing need for shelter since it affects them directly, yet they can't afford to pay for the essential expenditures associated with housing construction and environmental upkeep. 
habitation-ready settlements The more slum-like the circumstances of the settlements become, the less the amount of money that may be set aside for the maintenance of dwellings and other residential infrastructure.

As long as the slum continues to expand, conditions for those living there will only become worse. It will be simple to start fires, give possibilities for criminal activity, break moral standards, and lead to irregular land usage and frequent floods, all of which will increase environmental deterioration. In addition to being cruel, evicting slum urban settlements by linked parties does not totally address the problem since the settlers grab other vacant land so that if one slum is gone, two or more new ones would arise.

Despite this, the primary means of reducing poverty remains the advancement of humankind through social, economic, and environmental means. Environmental development, however, is given significant attention, which aims to create a residential environment that is favorable to many elements of human growth so that poverty reduction via complete human development (spiritual and material) may be promptly accomplished.

There must be efficient communication amongst all program actors in order to achieve the desired community behavior. Concept of area management is required for efficient communication. This notion is a way to teach people how to change the way they think, feel, and act in an organized community by using management science-based norms or agreements.

Slums are an issue that has to be addressed. The physical state of a slum community is one of three main considerations in a slum settlement research. It may be visible in a variety of ways: low-quality construction, unpaved and unpatterned roads, non-functioning sanitation and drainage and garbage that isn't adequately managed are just a few. Second, the social, economic, and cultural situations of the residents of these settlements. A culture of poverty pervades the lives of those who live in slums, as evidenced, amongst other things, by the people's indifferent attitudes and behaviors. Third, consider the results of these two circumstances. Poor health conditions, pollution, disease transmission and deviant behavior can all arise from living in these settings.

Slums are viewed as a sickness that must be fought against in the city. The growth of settlements is primarily driven by population expansion, but the quality of the settlements is influenced by the socioeconomic conditions of the community and the abilities of city administrators. As the population grows in poverty and the government is unable to manage expansion and provide basic urban amenities, slums are the result.

By 2030, 60 percent of the world's population will live in cities, and 70 percent by 2050, according to the UN. 450 cities will have populations greater than 1 million, including more than 20 megacities (those with populations greater than 10 million). A better life and a better career await those who move to Indonesia's cities that are thriving as hubs of activity and development. From year to year, the number of people moving to metropolitan regions grows. They come from all walks of life, some with a purpose and others not.

There are several issues to consider when it comes to planning for the growth of urban activities, including how to accept, regulate, and utilize migrants in the city's spatial planning system (Watson, 2019). There are pockets of activity that do not support each other, as well as the creation of communities that expand outside the plan so that slums are developed.

Due to the above-mentioned population issues and the government's restricted budget for urban planning and administration, housing and settlement amenities have also been limited and expensive to finance. Low-income or "poverty" persons are the ones most likely to be unable to meet their housing and settlement demands in metropolitan environments (Turner, 1968). 
According to the above example, the first item that is sacrificed when one has to meet the necessities of life, such as food, clothing or health care, is the spending for his home and dwelling.

Poor people with low wages have a dilemma: they can't ignore the pressing need for housing and shelter because it affects their daily lives, yet they also can't afford to pay for the essential expenditures associated with building and maintaining livable communities. The more slumlike the circumstances of the settlements become, the less the amount of money that may be set aside for the maintenance of dwellings and other residential infrastructure.

From 2000 to 2010, the number of impoverished people living in Bangladesh's 150 millionperson country dropped by nearly half, from 63 million to 46 million (TW 2013). According to the BBS (2010), poverty has decreased annually by 1.47 percent since 1991, and it was cut in half by 2012. However, despite the fact that 9.4 million poor people (21.3 percent of all urban regions) reside in metropolitan areas, this is often concentrated on the rural poor (BBS 2010). Landlessness is a result of poverty, as is a lack of access to essential services and educational and career possibilities. As a result, building up one's human capital becomes more challenging. Those living in cities with no social safety net are at greater risk of poverty and have a greater likelihood of staying that way.

As long as the slum continues to expand, conditions for those living there will only become worse. It will be simple to start fires, give possibilities for criminal activity, break moral standards, and lead to irregular land usage and frequent floods, all of which will increase environmental deterioration. Evictions by the relevant parties do not address the problem, and this way is harsh, since the settlers again grab other open ground such that if one is lost, two or more additional slums will arise if the first is gone.

Building essential infrastructure and utilities for settlements such as drinking water, sanitation, environmental roadways, rejuvenating the region, and increasing the quality of settlements are all part of the government's response to these difficulties. Communities are involved in all aspects of infrastructure development, from planning to operation and maintenance, and one of the government's initiatives toward realizing this vision is the Community-Based Settlement Environment (Kyessi, 2005).

\section{Health Management}

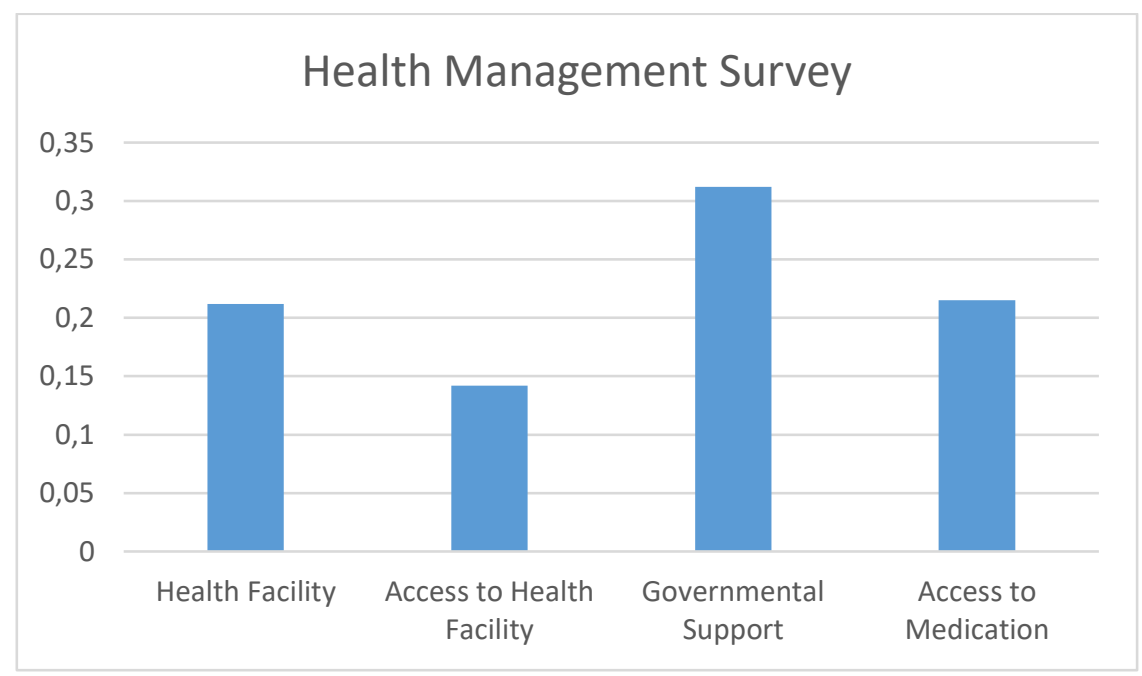

Figure 3. Surveys on health management

Slum settlements may be solved by giving people with resources and empowering them to make their own decisions (Boonyabancha, 2005). The major MDG strategy for sustaining gains

Copyright $@$ (2022, Journal of Asian Multicultural Research for Economy and Management Study, Under the license CC BY-SA 4.0 
is community empowerment achieved via participatory decision-making in development initiatives. SD necessitates the use of a community-driven participatory approach. People are more committed to projects when they are involved in its conception and implementation. Decentralized decision-making in government may increase community involvement, build capital, maintain resources, and offer services, all while improving resource management (Larson, 2002; Kofinas, 2009). In addition, community-based organizations (CBOs) provide more access to collective policies and solutions at the government level in democratic decisionmaking, as well as accountability and transparency in government leadership. Elites and politicians no longer have authority over local development initiatives.

There must be efficient communication amongst all program actors in order to achieve the desired community behavior. Concept of area management is required for efficient communication. An organized community can be taught to change their views, attitudes, and behavior via the use of management science-based norms or agreements.

The community's social elements that serve as a foundation for settlement growth: In order for society to function, there must be some kind of structure in place (Green \& Haines, 2015). Structure refers to any action or technique used by those in authority to govern, dominate and exploit.. One way in which social structure regulates human behavior is through acting as a barrier to free exchange between individuals and groups within a society.

Community-based organizations have the ability to foster involvement, advance development, and act as a go-between for community empowerment and individual growth (Osman, 2009). This helps strengthen both individual and collective capability and connectivity to SD. CBOs promote community welfare, health care, and women's skills in order to develop contact, social relationships, control, and self-confidence in the communities in which they operate. Identifying and addressing community problems as well as supporting CBOs' support for public input on decision-making is a cost-effective and sustainable method.

Benefits can't be sustained without better governance, which is why housing change must be institutionalized. Squatter settlements can be improved by communities themselves if they use a more open and responsible procedure. By empowering communities via participation, local capacity building, and institutional improvement, PBB (2005) advocates for a bottom-up approach to poverty reduction. International organizations are also shifting their focus from centralized development to community-driven development, placing a greater emphasis on incorporating the informal sector into decision-making processes.

\section{Public Housing}

There is a rising urbanization, overpopulation and poverty in developing nations because they are unable to eradicate informal settlements, cut supply or fulfill the LIG needs (Rana, 2011). LIG's access to land and housing is hindered by Bangladesh's policies and institutions. Because of their lack of access to financial resources, as well as a reluctance to take part in the decisionmaking process, they are marginalized. Only the most affluent people are served by government agencies and real estate developers when it comes to housing and land. The bulk of the impoverished were left without adequate housing and other basic necessities because the government failed to address these issues.

A substantial part of the informal economy serves the needs of low-income households since the government is unable to provide them with enough access to safe and cheap land and infrastructure and services. 85 percent of Dhaka's 1 million units belong to the private sector, while the public sector serves less than 10 percent of the city's residents. Programs that rely on funding from outside sources are not included in government policy. Because the government considers housing to be a non-productive good, the private sector is the only one who may 
invest in it. Site plots, subsidized services, and staff housing are centered mostly in Dhaka, despite the program's low returns. In the Fourth Five-Year Plan, the government admitted that it was unable to satisfy housing demand due to a lack of resources (1990-95).

2 In order to enhance supply through public-private partnership, gradually intervene to plan and develop land, infrastructure, and services, manage finances, and encourage private participation. People's life and working conditions will be improved through the 1995-2000 Plan, which will provide infrastructure, loans, and other services. Thus, the Slum Improvement Program was born, a series of initiatives designed to empower and strengthen the ability of the slum dwellers while also improving their social, economic, and environmental conditions.

\section{Bangladesh's Slum Reconstruction Program}

From 1982 to 1985, Bangladesh's Department of Social Services launched a project, financed by UNICEF, to research the underprivileged in four major cities. There will be GI Loans and health care for women, as well as childcare facilities and tube wells and latrines built in a number of bastes. As a result of an inexperienced team and a lack of resources, the project was put on hold. Therefore, LGED was tasked with facilitating and enhancing institutional interaction. There have been several initiatives since then that have included a variety of components. When it comes to alleviating poverty, LPUPA works with communities to build partnerships, empower women, and involve them in decision-making. The second phase of LPUPA and SBSUA was combined to operate through 2007 as a comparable UNICEF-funded Support for Basic Services to Urban Areas (SBSUA) Project. Technical support from UNCHS is provided via an Infrastructure Development Fund and an Alleviation of Poverty Fund for LGED's implementation of the program (training and GI). To preserve the project's advantages, Phase II involves the supply of savings and credit, as well as education and cleanliness, which were all included in Phase I. The Community Development Committee is in charge of distributing this (CDC). Credit groups formed by the borrowers are eligible for microcredit.

\section{Empowerment and Capacity Building}

Sustainable involvement, capacity-building, and empowerment are all intertwined. Enabling people or organizations to make better decisions and achieve better results is an important part of empowerment. An instrument for enhancing the assets and capabilities of local communities to influence the choices of the institutions that have an impact on their daily life. Allowing individuals to take part in decisions that affect their lives is a key component of empowerment. It may be used to influence project choices at the levels of the economy, politics, and institutions.

An emphasis on the necessity of empowerment in the implementation of development initiatives. This enables communities to build competence, self-confidence, and control over their own future growth. It's all about recognizing the advantages that people and communities get from being involved in the planning and decision-making process, improving their capacity via education, and exchanging their local expertise. Participation, organizational capability, and responsibility are all interconnected components of empowerment.

Government and non-profit organizations must deliver effective services in order to be considered sustainable (Fowler, 2013). The program's focus is on community engagement, which is related to development and social phenomena that spread. Empowering communities helps them overcome obstacles to a decent standard of living and puts pressure on institutions and policymakers to make necessary changes to access to resources and the quality of life they provide for their members. These community-based participatory activities will assist people in increasing their collective action capacity, which will lead to major development outcomes, 
such as greater access to basic needs and a higher standard of living, as well as expanded inclusion and equity.

Enhance the community's ability to identify, evaluate, and respond to issues that affect its members through the process of capacity building. Communities may use their resources and abilities to improve their strengths and address issues in their own backyards. When it comes to long-term success in urban development, economics advocates for the well-being of the state by promoting reforms in the areas of property rights and good governance.

The technical expertise of development organizations as well as readily accessible resources may be put to good use with the right kind of empowerment (Ripley \& Ripley, M1992). CBOs with managerial competence can act as a bridge between individuals and institutions, while participants' self-help resources and local knowledge also play a role. Transparency and participation in decision-making may help transform environmental improvements into concrete plans of action and collaborations. International organizations assist in the development of institutions and the deregulation of land and housing markets because of weak institutions, bias, corruption, and market manipulation.

\section{Approach to Bastees}

"the slums of hope" because of their practical functions. Despite this, they are rarely tolerated by the state. These bastees are despised by the Bangladeshi authorities. 3 Even while evictions are in effect, they are only redistributing poverty to less desirable locations. Slum Eradication Committee, Task Force Report, and National Housing Policy all advocated raising bastees in 1990, 1990, and 1993, respectively.

The potential of the impoverished to improve their living conditions and hence their productivity and income is demonstrated by the housing projects implemented by nongovernmental organizations (NGOs). However, they are unable to possess their own land. This project was made possible by the Development Agency Association and government-nonprofit partnership, which resulted in a low cost 16,000-unit complex. It neglects the requirement for a living environment with basic facilities and reasonable rates..

\section{Conclusion}

Research on slum settlements must take into account the physical condition of a community as one of the three key aspects. Living under these conditions can lead to a variety of negative consequences, including decreased health, increased pollution, the spread of illness, and even criminal conduct. It is considered a disease in the city to have slums. It is considered a disease in the city to have slums. Build a residential environment that is conducive to various aspects of human progress in order to quickly achieve poverty reduction via comprehensive human development. With the help of community-based organizations (CBOs), individuals and communities alike may be empowered and enriched. Bottom-up approaches to poverty reduction are promoted by united Nation, which emphasizes community engagement, local capacity building, and strengthening of institutions as means of reducing poverty. Workers in the informal sector face low wages, long hours, and the possibility of losing their jobs. Over half the populace is not satisfied with eight of the eleven services. It is difficult for LIG to get access to land and houses because of Bangladesh's regulations and institutions. For the duration of the UNICEF-funded initiative, Bangladesh's Department of Social Services studied the disadvantaged in four major cities between 1982 and 1985. Women's empowerment and participation in decision-making are LPUPA's primary goals in working with communities to develop relationships and empower women. Encouraging sustained participation, capacity development, and individual agency are all linked concepts. Communities that are empowered are better able to overcome challenges to a reasonable quality of living. " It puts pressure on 
institutions and governments to make essential reforms to their members' access to resources and the quality of their lives.

\section{References}

Boonyabancha, S. (2005). Baan Mankong: Going to scale with "slum" and squatter upgrading in Thailand. Environment and Urbanization, 17(1), 21-46.

Fowler, A. (Ed.). (2013). Striking a balance: A guide to enhancing the effectiveness of nongovernmental organisations in international development. Routledge.

Green, G. P., \& Haines, A. (2015). Asset building \& community development. Sage publications.

Kofinas, G. P. (2009). Adaptive co-management in social-ecological governance. In Principles of ecosystem stewardship(pp. 77-101). Springer, New York, NY.

Kyessi, A. G. (2005). Community-based urban water management in fringe neighbourhoods: the case of Dar es Salaam, Tanzania. Habitat International, 29(1), 1-25.

Larson, A. M. (2002). Natural resources and decentralization in Nicaragua: Are local governments up to the job?. World Development, 30(1), 17-31.

Osman, S. W. (2009). Identifying the organizational changes taking place in Somali community-based organization (CBO) in response to new patterns of immigration: implications for adult community education.

Rana, M. M. P. (2011). Urbanization and sustainability: challenges and strategies for sustainable urban development in Bangladesh. Environment, Development and Sustainability, 13(1), 237-256.

Ripley, R. E., \& Ripley, M. J. (1992). Empowerment, the cornerstone of quality: empowering management in innovative organizations in the 1990s. Management decision.

Turner, J. C. (1968). Housing priorities, settlement patterns, and urban development in modernizing countries. Journal of the American Institute of Planners, 34(6), 354-363.

Watson, V. (2009). 'The planned city sweeps the poor away...': Urban planning and 21st century urbanisation. Progress in planning, 72(3), 151-193 